\title{
Astrocytes in Amyotrophic Lateral Sclerosis
}

\author{
Sandra H. Vaz ${ }^{1,2} \bullet$ Sara Pinto ${ }^{1,2} \bullet$ Ana M. Sebastião ${ }^{1,2} \bullet$ Dora Brites $^{3,4}$ \\ ${ }^{1}$ Instituto de Medicina Molecular João Lobo Antunes, Faculdade de Medicina, \\ Universidade de Lisboa, Lisboa, Portugal; ${ }^{2}$ Instituto de Farmacologia e Neurociências, \\ Faculdade de Medicina, Universidade de Lisboa, Lisboa, Portugal; ${ }^{3}$ Instituto de \\ Investigação do Medicamento (iMed.ULisboa), Faculdade de Farmácia, Universidade de \\ Lisboa, Lisboa, Portugal; ${ }^{4}$ Departamento de Ciências Farmacêuticas e do Medicamento, \\ Faculdade de Farmácia, Universidade de Lisboa, Lisboa, Portugal
}

Authors for correspondence: Sandra H. Vaz, Instituto de Medicina Molecular João Lobo Antunes, Faculdade de Medicina, Universidade de Lisboa, Lisboa, Portugal. E-mail: svaz@medicina.ulisboa.pt; Dora Brites, Faculdade de Farmácia, Universidade de Lisboa, Lisboa, Portugal. Email: dbrites@ff.ulisboa.pt

Doi: https://doi.org/10.36255/exonpublications.amyotrophiclateralsclerosis. astrocytes. 2021

\begin{abstract}
Amyotrophic lateral sclerosis (ALS) is a devastating neurodegenerative disorder, characterized by the degeneration of upper and lower motor neurons of the motor cortex, brainstem, and ventral horn of the spinal cord. The role of glial cells in the onset and progression of ALS is increasingly being recognized. Dysfunctional astrocytes, with an atypical and neurotoxic phenotype, in the cerebral cortex and the spinal cord promote neuroinflammation and motor neuron degeneration. Indeed, cortical and spinal cord astrocytes from SODIG93A (mSODl) mice are neurotoxic, develop early deficits, and lose their neurosupportive properties before disease onset. This chapter discusses the contribution of dysfunctional cortical and spinal cord astrocytes in the development and
\end{abstract}

In: Amyotrophic Lateral Sclerosis. Araki T (Editor), Exon Publications, Brisbane, Australia. ISBN: 978-0-6450017-7-8. Doi: https://doi.org/10.36255/exonpublications. amyotrophiclateralsclerosis. 2021

Copyright: The Authors.

License: This open access article is licenced under Creative Commons Attribution-NonCommercial 4.0 International (CC BY-NC 4.0) https://creativecommons.org/licenses/by-nc/4.0/ 
progression of ALS. Differences in astrocyte heterogeneity and reactivity, calcium signaling, neurotransmitters, and in paracrine signaling mechanisms along with implications for novel therapies in ALS are addressed.

Keywords: amyotrophic lateral sclerosis; astrocyte subpopulations; glutamate and homeostatic imbalance; reactive biomarkers; revival of dysfunctional astrocytes

\section{INTRODUCTION}

Amyotrophic lateral sclerosis (ALS) is a progressive and devastating neurodegenerative disorder, characterized by the degeneration of upper and lower motor neurons (MNs) across the corticospinal tract, from the motor cortex to the brainstem, and ventral horn of the spinal cord (SC) (1). The disease progression is aggressive, with a fatal outcome usually within five years of onset. Currently, there is no cure and very few treatments are available for this devastating MN disease. While most cases of ALS are sporadic (sALS) (90-95\%), a small subset (5-10\%) of patients have a positive familial history (fALS) (2). Mutations in the gene encoding for the $\mathrm{Cu}^{2+} / \mathrm{Zn}^{2+}$ ion-binding superoxide dismutase (SOD1) protein are the most common and represent approximately $20 \%$ of fALS cases. SODIG93A mouse (mSODl) is currently the most widely used animal model to study ALS. Other mutations associated to ALS are TARDBP (also known as TDP-43; encodes for TAR DNA-binding protein), FUS (encodes RNA-binding protein Fused in Sarcoma/Translocated in Sarcoma), ANG (encodes angiogenin, ribonuclease, RNase A family, 5), and OPTN (encodes optineurin) (2). The most common mutations associated to ALS and frontotemporal dementia, a variant of ALS, are the gain of toxicity by the nucleotide GGGGCC repeat expansions within the gene C9ORF72 (3).

The relevance of glial cells on the onset and progression of ALS is now recognized. In genetically modified mice, in which the SOD 1 mutation was selectively excised from different central nervous system (CNS) cell types, it was observed that different glial cells significantly promote disease progression (4). Among these, dysfunctional astrocytes, with an aberrant and neurotoxic phenotype in the cerebral cortex and the SC of mSODl mice, were recognized as major contributors. ALS astrocytes develop early deficits and lose neuro-supportive properties, secreting toxic factors that directly induce MN cell death $(5,6)$. In this chapter, we discuss the role of dysfunctional astrocytes in ALS with emphasis on astrocyte reactivity and heterogeneity, neurotransmitter transporters, and dysregulation of autocrine and paracrine mechanisms.

\section{ASTROCYTIC REACTIVITY AND HETEROGENEITY}

The exact mechanisms for neuronal degeneration in ALS are still unclear, but astrocytes are recognized as important players in both upper and lower MN loss (4). Neuroinflammation and glial activation are observed at the onset of, and during, disease progression. Astrocytes express differential astrocytic receptors, 
transporters, and neurotransmitters, and release neurotrophic factors, inflammatory mediators and cytotoxins. These reactive astrocytes are observed in the cortex and SC of ALS patients, both in sALS and fALS cases (7). Glial cell proliferation and activation are found not only in motor areas, but also in non-motor areas, such as hippocampus, of mSODl rats, starting at the presymptomatic stage of the disease (8). SC mSODl astrocytes from newborn pups were shown to cause MN toxicity, long before any visible reactive gliosis (5). In ALS, these reactive astrocytes lose their physiological and homeostatic functions and acquire a neurotoxic and aberrant phenotype (5). Transplantation of SODl glial-restricted precursor cells into the SC of healthy rodents showed to differentiate into neurotoxic astrocytes and trigger MN degeneration (9), whereas transplantation of normal astrocyte precursors delayed disease progression and extended the survival of mSOD1 rats (10). Astrocytes derived from sALS patients also led to MN degeneration after transplantation into mice (11). Thus, the identification of specific mechanisms and mediators of astrocyte toxicity offers important insights into the pathways of MN degeneration in ALS and the ways to prevent them. Both upper and lower MNs are affected in ALS, and astrocytes reveal regional diverse phenotypes, as depicted in Figure 1.

Cortical and SC astrocytes cause neuronal dysfunction by specific and common pathological mechanisms (12). This is in line with the recent concept of astrocyte heterogeneity, either in the same zone of the CNS or across different regions (13). Reactive astrogliosis and graded reactions depend on microenvironmental cues and interactions between neighboring cells, as well as on autocrine signaling (14). In the mSODl mouse model, cortical astrocytes present an early hypertrophic/fibroblast-like morphology and a reactive and inflammatory phenotype. Such phenotype is characterized by decreased expression of glial fibrillary acidic protein (GFAP) and increased cell proliferative capacity, as well as elevated expression of S100 calcium $\left(\mathrm{Ca}^{2+}\right)$-binding protein B (S100B) and high mobility group box protein 1 (HMGB1). SC astrocytes appear to be more constrained than cortical ones, mainly in the presymptomatic stage, with decreased S100B and HMGB1 expression levels $(12,15)$. In late stages, a marked proliferative capacity and overexpression of S100B and HMGB1 is observed in astrocytes from the SC of ALS patients, and rodent models $(16,17)$.

GFAP is the hallmark intermediate filament protein in astrocytes and its upregulation is usually associated with reactive astrogliosis (18). However, GFAP amount in adjacent astrocytes is extremely heterogeneous, as well as its expression in different regions $(19,20)$. Reactive GFAP-astrocytes were found in the ventral horn of ALS patients (21), with elevated appearance in the cerebrospinal fluid (CSF) relative to other neurologic diseases (22). Astrocytes with increased GFAP content and multiple inflammatory/reactive mediators were also identified in the SC of adult mice (23). While differential distribution of GFAP immunoreactivity was found in the white matter of the SC at early symptomatic transgenic mSODl mice, in the gray matter that was found only in the end-stage disease (24). In other studies, GFAP expression did not show differences between mSOD1 and wild-type mice at 40 and 80 postnatal days, but strongly increased at terminal stages in the SC of mSODl mice (25). In contrast, our studies evidenced decreased levels of GFAP in the pre-symptomatic stage in the cortical brain (15) and in the $\mathrm{SC}$ of mSODl mice (17). Decreased GFAP expression levels were also found in astrocytes isolated from the brain cortex of mSODl pups, which presented 


\section{Cortical astrocytes}
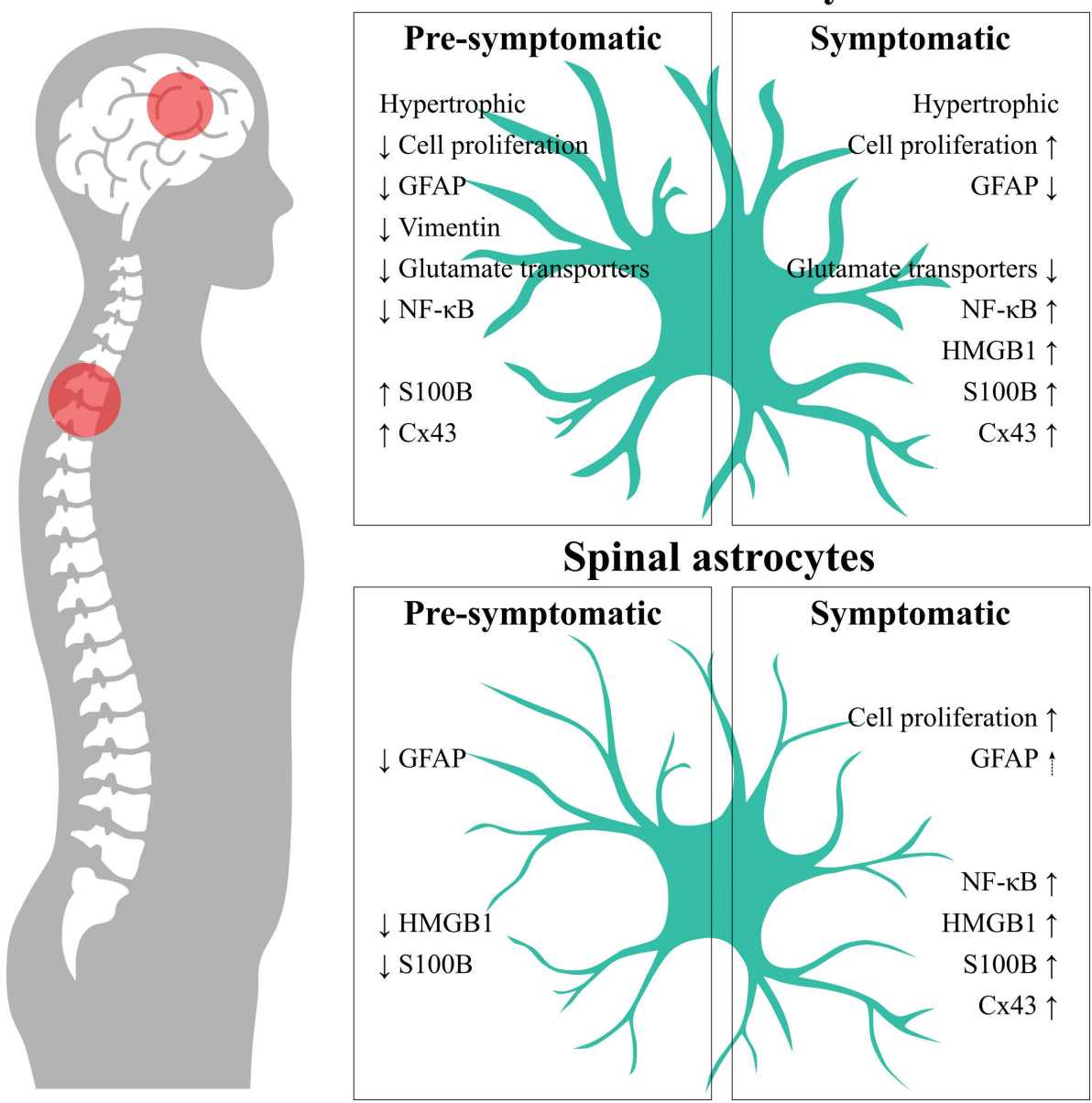

Figure 1. Astrocyte regional diversity and heterogeneity in ALS. Astrocytes in ALS are known to have an aberrant and reactive profile, expressing different astrocytic markers depending on their location in the central nervous system (cortical or spinal astrocytes), and stage of the disease (pre-symptomatic and symptomatic). Cortical astrocytes are less proliferative in the pre-symptomatic stage, where they show a decreased expression of GFAP, vimentin, glutamate transporters and NF-kB, and an increased expression of S100B and Cx43 (12, 15). In the symptomatic stage of the disease, cortical astrocytes are more proliferative, showing an increased expression of NF-kB, HMGB1, S100B and Cx43, together with a reduction of glutamate transporters and GFAP $(12,15)$. Spinal astrocytes in the pre-symptomatic stage exhibit a decreased expression of GFAP, S100B and HMGB1, while in the symptomatic stage astrocytes present a proliferative profile with increased expression of NF-kB, S100B, HMGB1 and Cx43. The expression of GFAP in the symptomatic spinal astrocyte has been shown to increase or decrease, depending on the model, condition or region used in the study $(16,17$, $23,24)$. Altogether, these data demonstrate the high diversity and heterogeneity of astrocytes in ALS. ALS, amyotrophic lateral sclerosis; Cx43, connexin-43, GFAP, glial fibrillary acidic protein; HMGB1, high mobility group box protein 1; miRNA-146a, microRNA-146a; NF-kB, nuclear factor kappa; S100B, S100 calcium-binding protein B. 
aberrant astrocytic markers [increased S100B, connexin 43 (Cx43), Ki-67, and vimentin, together with decreased GFAP, glutamate transporter-1 (GLT-1) and glutamate/aspartate transporter (GLAST)], as found in the same region at the symptomatic stage (15). Such acquired "immature" or dedifferentiated astrocyte phenotype is neurotoxic and disease-specific in the cortical brain, and probably associated with the bulbar origin of the disorder (12). The early occurrence of such signature in 7-day-old astrocytes from the brain cortex of mSODl mice was also observed in other disease models and related with the loss of neurosupportive functions (26). Decreased expression of GFAP was similarly found in glial cell populations from the SC of symptomatic mSOD1 rats (16). When expression of mSODl was virally induced in cortical astrocytes, alterations in cell morphology and density, together with low GFAP immunostaining were obtained (27). However, the loss of GFAP only marginally accelerated disease progression in the SOD1H46R transgenic mice (28). In sum, GFAP is not an absolute marker of reactivity, nor it strictly correlates with the disease severity. Variations in animal models, regional diversity, and specific astrocyte subpopulations may be the reason for the disparate data found in the literature.

Increased expression of HMGB1 in reactive glia may lead to the activation of toll-like receptor/receptor for advanced glycation end-products (TLR/RAGE) signaling pathways, and contribute to the progression of inflammation and MN injury (29). S100B is a $\mathrm{Ca}^{2+}$-binding protein that is highly expressed in astrocytes and, depending on its concentration, can have beneficial or deleterious effects. In ALS, S100B levels are increased in the CSF, positively correlating with a worse prognosis of the disease (30). The inhibition of S100B downregulates the expression of GFAP and cytokines, such as tumor necrosis factor (TNF)- $\alpha, C-C$ motif chemokine ligand 6 (CCL6), and C-X-C motif chemokine ligand 10 (CXCL10), indicating its association to a proinflammatory phenotype in $\mathrm{mSODl}$ astrocytes. Expression and release of pro-inflammatory cytokines lead to the activation of the nuclear factor kappa B (NF-kB) signaling cascade, a regulator of reactive gliosis and inflammation. In early stages of ALS, NF-kB activation in SC astrocytes can induce a neuroprotective phenotype, by promoting beneficial microglia activation and delaying disease progression. However, prolonged NF- $\mathrm{kB}$ activation in later stages exacerbates the immune response with pro-inflammatory microglial activation, gliosis, and disruption of the blood-SC barrier (31). Communication among astrocytes is promoted by connexin-based gap junctions, such as Cx43. Abnormally high Cx43 expression in the cortical and SC astrocytes of mSOD1 mice and ALS patients is associated to astrocyte-mediated neurotoxicity (32).

Astrocytes in ALS release soluble toxic factors that promote MN degeneration (16), but still not clearly identified. Upregulation of the major histocompatibility complex I (MHC-I) in MNs seems to be associated with a slower disease progression (4). However, astrocytes in both $\mathrm{mSODI}$ mice and ALS patients were shown to downregulate the expression of MHC-I in MNs, by causing endoplasmic reticulum (ER) stress, thus increasing their susceptibility to astrocyte-induced cell death (33). On the other hand, reactive astrocytes secrete increased transforming growth factor (TGF)- $\beta 1$ that causes MN autophagic dysregulation, abnormal protein aggregation, and cellular toxicity (23). Astrocytes, when exposed to the CSF from ALS patients, release pro-inflammatory cytokines, such as interleukin (IL)-6, TNF- $\alpha$, and interferon (IFN)- $\gamma$, together with increased levels of glutamate, reactive oxygen species, and nitric oxide, causing neurotoxicity. These in turn lead to 
a downregulation of neurotrophic factors, such as vascular endothelial growth factor (VEGF) and glial cell line-derived neurotrophic factor (GDNF) (34), as detailed below. In ALS, activated microglia secrete IL- $1 \alpha$, TNF- $\alpha$, and complement component lq (Clq), known to induce neurotoxic reactive astrocytes (35). Abrogation of IL-1 $\alpha$, TNF- $\alpha$, and Clq was shown to reduce astrogliosis and extend $\mathrm{mSOD} 1$ mouse survival. In the absence of reactive astrocytes, $\mathrm{MN}$ death is significantly delayed (36). The major mechanisms leading to MN degeneration are summarized in Figure 2.

Aberrant TDP-43 aggregation, a pathological hallmark of both ALS and frontotemporal dementia, was found in astrocytes and shown to contribute to neurodegeneration through cell-specific mechanisms (37). Astrocytes expressing mutated C9ORF72 show a deficient expression of antioxidant proteins, such as SOD1, SOD2 and peroxiredoxins (38). Altogether, astrocytes in ALS not only have a reactive and inflammatory phenotype, but also show impaired protective functions, which may be even exacerbated by the activation of other glial cells such as microglia (35). All these features indicate that astrocytes participate in the control and maintenance of homeostatic balance but, when dysregulated, they lead to neuroinflammation and MN death, thus supporting astrocyte's key role in the onset and progression of ALS. It is not known if the appearance of an aberrant astrocyte signature previous to ALS symptom onset, in the brain cortex, results from intrinsic cell deficiencies or whether it is determined by MN paracrine pathological signaling. Dysregulated GFAP, $\mathrm{S} 100 \mathrm{~B}$, and the marker of proliferation, Ki-67, in immature cortical astrocytes of mSODl pups agree with the first hypothesis. Identification of disease-specific astrocytic subpopulations will have a high impact on the understanding of their pathological role in ALS, and on their targeting toward the recovery of a neuroprotective phenotype.

\section{GLUTAMATE AND GABA TRANSPORTERS}

Alterations in excitatory neurotransmission appear to play a role in ALS. Hyperexcitability has been observed in sALS and fALS patients before the onset of symptoms, and also in presymptomatic mSODl mouse models. However, other studies showed hypoexcitability, rather than hyperexcitability, prior to degeneration $(1,37,39)$. Thus, it is still unclear whether hyperexcitability leads to MN degeneration or if it is a compensatory mechanism resulting from MN loss. Astrocytes sustain homeostatic levels of extrasynaptic glutamate within the synaptic cleft to control synaptic transmission, mainly through specific glutamate transporters, such as GLAST and GLT-1 (40). The GLT-1 transporter is found exclusively in astroglia, both in brain and SC, and is responsible for the uptake of nearly $90 \%$ of the glutamate. One of the proposed mechanisms for MN death in ALS is glutamate-mediated excitotoxicity (1), since impaired glutamate clearance was shown in astrocytes expressing $\mathrm{mSOD} 1$ and TDP-43, suggesting a common pathological feature in ALS (Figure 3A) (41, 42).

Defects in glutamate uptake by GLT-1 were found in the SC of ALS patients in regions of MN loss (43), in mSODl rodents (44), and in TDP-43 mice (45). 


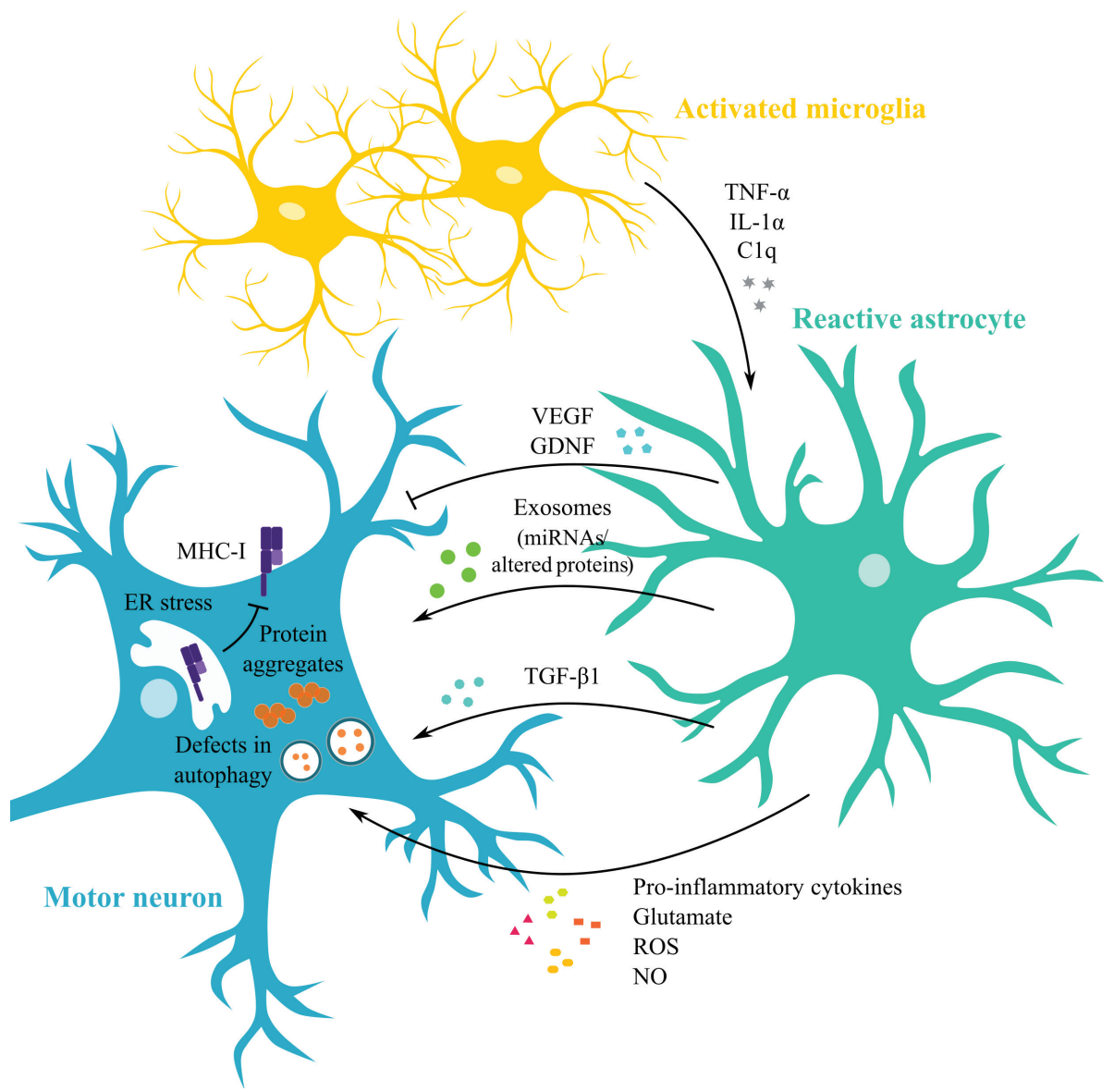

Figure 2. Reactive astrocytes promote MN degeneration in ALS. Astrocytes are known to have an aberrant and reactive profile in ALS, releasing several soluble toxic factors and inflammatory mediators that render MNs more susceptible to degeneration. Astrocytes respond to factors released to the milieu by activated microglia, such as TNF- $\alpha$, IL-1 $\alpha$ and C1q. Reactive astrocytes secrete high levels of pro-inflammatory cytokines, glutamate, ROS and NO, as well as lower levels of neurotrophic factors, such as VEGF and GDNF (34). Moreover, astrocytes can downregulate the expression of MHC-I in MNs, by causing ER stress and making them more susceptible to astrocyte-induced cell death (33). Reactive astrocytes also promote defects in autophagy by secretion of TGF- $\beta 1$ and activation of the rapamycin signaling pathway in MNs (23). Besides soluble factors, exosomes derived from ALS astrocytes also transfer miRNAs and mutant and misfolded proteins to neighboring cells $(35,36)$. Altogether, astrocytes can contribute to abnormal protein aggregation and cellular toxicity. ALS, amyotrophic lateral sclerosis; C1q, complement component 1q; ER,

endoplasmic reticulum; GDNF, glial cell line-derived neurotrophic factor; IL-1 $\alpha$, interleukin 1 alpha; miRNA, microRNA; MHC-I, major histocompatibility complex I; MNs, motor neurons; $\mathrm{NO}$, nitric oxide; ROS, reactive oxygen species; TGF- $\beta 1$, transforming growth factor beta 1 ; TNF- $\alpha$, tumor necrosis factor alpha; VEGF, vascular endothelial growth factor. 


\section{A. Uptake}

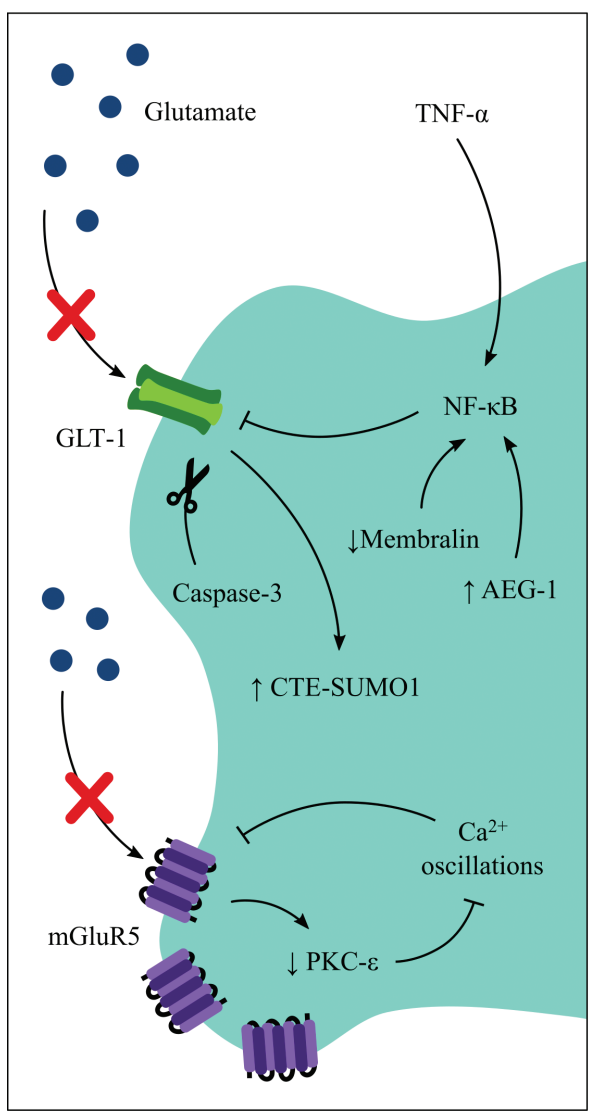

B. Release

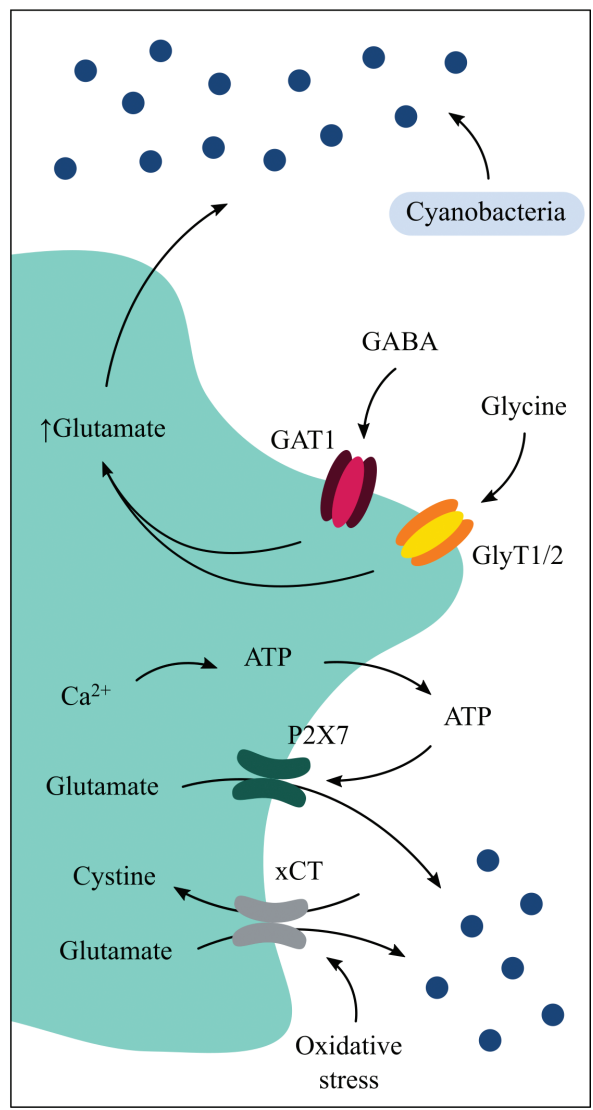

Figure 3. Glutamate-mediated excitotoxicity in ALS. A. In ALS, the astrocytic glutamate transporter GLT-1 is downregulated, leading to an impaired glutamate uptake, and the TNF- $\alpha /$ TNFR1/NF-kB pathway modulates its expression levels (48). Membralin is reduced in the spinal cord of ALS patients and ALS mouse models, and its deletion was shown to suppress GLT-1 expression through the TNF- $\alpha$ /TNFR1/NF-kB pathway (49). AEG-1 is upregulated in ALS and its silencing restores GLT-1 expression and inhibits NF- $\mathrm{kB}$ signaling (50). Caspase-3 cleaves GLT-1 and leads to the accumulation of a sumoylated C-terminus fragment, the CTE-SUMO1. The accumulation of this fragment causes astrocytes to alter their phenotypes and secrete toxic factors to MNs (51). Metabotropic glutamate receptors, such as mGluR5, are overexpressed in ALS, but their function was shown to be altered. PKC- $\varepsilon$ is reduced in astrocytes, leading to the generation of atypical $\mathrm{Ca}^{2+}$ oscillations and impaired glutamate uptake $(58,59)$. B. Glutamate release has been shown to be abnormally increased in ALS. Exposure to GABA or glycine leads to an abnormal GAT1 or GlyT1/2-mediated glutamate release (62). Astrocytes also release high levels of glutamate through the upregulation of cystine/glutamate antiporters (xCT), in response to oxidative stress (65). Elevated symbiotic Cyanobacteria increases glutamate, linking gut microbiota to ALS (66). AEG-1, astrocyte elevated gene 1; ALS, amyotrophic lateral sclerosis; $\mathrm{Ca}^{2+}$, calcium; GABA, gamma aminobutyric acid; GAT1, GABA transporter type 1; GlyT, glycine transporter; GLT-1, glutamate transporter 1 ; mGluR, metabotropic glutamate receptor 5 ; MNs, motor neurons; NF-кB, nuclear factor-kappa B; PKC- $\varepsilon$, protein kinase C-epsilon; TNF- $\alpha$, tumor necrosis factor alpha; TNFR1, tumor necrosis factor receptor $1 ; x C T$, cystine/glutamate antiporters. 
Several pathways have been implicated in the modulation of GLT-1 levels: (i) TNF- $\alpha$ and downstream NF-kB signaling have been shown to suppress GLT-1 expression (46); (ii) the specific deletion of the ER-component membralin causes a dramatic accumulation of extracellular glutamate, inducing MN glutamatergic toxicity (47); and (iii) decreased GLT-1 expression and glutamate uptake also occur as result of increased astrocyte elevated gene-1 (AEG-1) in mSODl astrocytes (48). Moreover, GLT-1 cleavage may derive from the action of caspase-3, with accumulation of a sumoylated GLT-1 C-terminus fragment early on the disease, causing astrocyte phenotypic aberrancies and release of neurotoxic factors (49). Modulation of GLT-1 to potentially prevent excitotoxicity has been attempted. Although, SC focal restoration of GLT-1 expression in astrocytes was not effective (50), enhanced GLT-1 translation by LDN/OSU-0212320 delayed MN function decline and extended the lifespan of mSODl mice (51). MC1568, an inhibitor of the enzymes Class-II histone deacetylases, restored GLT-1 expression and glutamate uptake in the SC of mSODl mice, but did not prolong their survival (52). Activation of the metabotropic glutamate receptors (mGluRs), mGluRl and mGluR5, leads to increased intracellular $\mathrm{Ca}^{2+}$ and facilitates glutamate transport (53). In line with this, when the overexpression of dysfunctional mGluR1 and mGluR5 in reactive SC astrocytes from ALS patients and mSOD1 mice was reduced, it prevented excessive glutamate release, improved the function of MNs, astrocytes and microglia, and increased animal survival $(54,55)$. Deficient glutamate uptake was linked to altered mGluR5-mediated $\mathrm{Ca}^{2+}$ signaling profile (56). By restoring $\mathrm{Ca}^{2+}$ oscillations in astrocytes from mSODl rats, mGluR5-mediated glutamate uptake was recovered (Figure 3A) (57). While glutamate is the major excitatory neurotransmitter in the CNS, gamma-aminobutyric acid (GABA) and glycine are the main inhibitory neurotransmitters. Raiteri et al. have shown that the activation of a glycine transporter on SC MNs caused enhanced glutamate release in a mouse model of ALS (58). Moreover, in the SC glutamatergic synaptic boutons of mSOD1 mice, the impact of synaptic vesicle exocytosis on the trafficking of nerve terminal GABA transporter-1 (GAT-1) and of type-1/2 glycine (Gly) transporters (GlyT-1/2) was studied by monitoring membrane expression and function of these transporters. It was observed that the enhanced exocytosis in $\mathrm{mSOD} 1$ mice boosts heterotransporter membrane expression, which evokes excessive glutamate release (Figure 3B) (59). GlyTl/2 and GATl are widely expressed in astrocytes and gliosomes (60), together with GABA and glutamate transporters. GABA-induced release of glutamate from SC gliosomes is enhanced in mSODl mice (61). Astrocytes were also shown to release higher levels of glutamate, through cystine/glutamate antiporters, in response to oxidative stress (62). SOD1 mutation was shown to reduce intracellular lactate levels and its secretion by astrocytes (63). Studies linking ALS with gut microbiota composition identified that elevated symbiotic Cyanobacteria could promote the elevation of glutamate, in contrast to the general Lactobacillus, Bifidobacterium, and Odoribacter-all known to metabolize glutamate (64). These findings open an all-new window of opportunities to characterize microbiota changes as ALS biomarkers and microbial strategies to improve health status quality of ALS patients. 


\section{DYSREGULATED AUTOCRINE/PARACRINE SIGNALING MECHANISMS}

Astrocytes have a unique form of excitability, which is characterized by intracellular $\mathrm{Ca}^{2+}$ oscillations or waves in response to physiological and pathophysiological signals. Intracellular $\mathrm{Ca}^{2+}$ elevation is triggered by several mechanisms, such as: (i) activation of Gq-protein-coupled receptors (GPCRs); (ii) GABAB receptor (Gi-coupled GPCRs) activation (65); and (iii) transient receptor potential (TRP) channels (66). Spatially restricted $\mathrm{Ca}^{2+}$ transients in astrocyte microdomains are associated with mitochondria (67). Altogether, they promote the release of gliotransmitters, such as glutamate, D-serine, GABA and neurotoxic factors (68).

The pathogenic potential of $\mathrm{Ca}^{2+}$ dysregulation in astrocytes may account for disease progression. ALS astrocytes show mitochondrial functional deficiencies and impaired $\mathrm{Ca}^{2+}$ homeostasis that promotes MN degeneration (69). In the SC of young mSODl mice, the enhanced expression of mGluR5 makes astrocytes vulnerable to glutamate, and causes persistent elevation of intracellular $\mathrm{Ca}^{2+}$ concentrations, which are reverted by Bcl-XL, and protein kinase C epsilon (Figure 3A) $(57,70)$. Administration of the mGluR5 antagonist 2-methyl-6-(phenylethynyl) pyridine (MPEP) slowed astrocyte degeneration, delayed disease onset and extended mSOD1 mouse survival (71). Also, purinergic stimulation of SC and cortical SODl-expressing astrocytes caused ER $\mathrm{Ca}^{2+}$ accumulation and abnormal $\mathrm{Ca}^{2+}$ signaling (72). The increased expression of $\mathrm{Cx} 43$ in $\mathrm{mSOD} 1$ mice also has a significant impact on $\mathrm{Ca}^{2+}$ signaling (73). Intracellular $\mathrm{Ca}^{2+}$ increase in astrocytes leads to the release of gliotransmitters, including glutamate, D-serine, GABA, brain derived neurotrophic factor (BDNF), as well as neurotoxic factors (68). Since astrocytes in ALS reveal many pathogenic changes, such as disrupted receptor-mediated $\mathrm{Ca}^{2+}$ signaling and mitochondrial functional deficiencies, it is anticipated that an impaired gliotransmitter release from ALS astrocytes will play a major role in $\mathrm{MN}$ pathology.

The storage and release of bioactive molecules by astrocytes involve mechanisms of exocytosis, diffusion through plasma membrane channels, and translocation by plasma membrane transporters. The soluble $N$-ethylmaleimide-sensitive factor attachment protein receptor (SNARE)-dependent vesicular exocytotic release is one of the major pathways for astrocyte secretion. ER $\mathrm{Ca}^{2+}$ release induces elevated ATP in mSODI astrocytes, which can be inhibited by the overexpression of dominant-negative SNARE to prevent toxicity to MNs and delay disease onset in mSOD1 mice (72). Similarly, pharmacological inhibition of P2X7 receptor abolished astrocyte toxicity towards MNs through degradation of extracellular ATP in mSOD1 mice $(74,75)$. Since P2X7 receptors form pores under pathophysiological conditions, P2X7 may function as membrane channels that allow the release of glutamate or toxic agents, thus accounting for ALS progression (Figure 3B).

Neurotrophic factors, in particular neurotrophins, are crucial for neuronal differentiation, maturation and survival, as well as for the modulation of synaptic transmission and plasticity (76). They are also potential therapeutic targets for neurodegenerative disorders, such as ALS (77). The neurotrophin family is composed of four members: nerve growth factor (NGF), BDNF, neurotrophin-3 (NT-3) and neurotrophin-4 (NT-4). BDNF is abundantly expressed in the CNS, where it 
supports neuronal survival (e.g., MNs) (77). SC astrocytes from mSODl mice respond to HMGB1 by decreasing BDNF and GDNF production, in contrast to wild-type astrocytes (78). Also, as previously mentioned, astrocytes exposed to the CSF of ALS patients, besides releasing neurotoxic factors, release lower levels of VEGF and GDNF (34).

ALS pathophysiology is intimately related with neuroinflammatory processes, which include the release of both neuroprotective and/or neurotoxic factors that play a role in MN pathology (79). Several studies have shown that TGF- $\beta$ signaling is involved in ALS and that TGF- $\beta 1$ release from astrocytes accelerates disease progression in ALS mice (23). Extracellular vesicles with 40-160 nm, denominated exosomes, are released from mSODl astrocytes and were shown to contain mutant SODl and dysregulated cargo in miRNAs, accounting for MN pathology and homeostatic imbalance $(80,81)$. miRNAs are small non-coding RNAs that control posttranscriptional expression of target genes (82). Dying neurons in ALS release miRNAs, such as miRNA(miR)-218, that can change the phenotype of astrocytes into a reactive one and cause the downregulation of GLT-1 (83). In most cases, exosomal cargo in miRNAs recapitulate their cell of origin $(84,85)$. Dysregulated expression of miRNAs was found in $\operatorname{ALS}(86,87)$ and proposed as biomarkers (88). Upregulation of miR-155 was identified in fALS and sALS patients, as well as in the SC of mSODl mice, in pre-symptomatic and symptomatic stages (17). In contrast, a decreased cargo in miR-494-3p was found in C9ORF72 astrocyte-derived exosomes with harmful consequences in neurite network in ALS (89). Depleted levels of miR-146a were also recognized in exosomes from the cortical astrocytes of mSOD1 mice (15), and its cellular replenishment abrogated the astrocyte aberrant phenotype, characterized by increased S100B and $\mathrm{Cx} 43$ levels, together with decreased GFAP, while leading to a secretome with paracrine neuroprotective properties (81). Exosomes from both cortical and spinal mSODl astrocytes were deficient in miR-155, miR-21 and miR-146a (12). Exosomes with low levels of miRNAs may lead to paracrine dysregulation and dysfunction of recipient cells, while also activating immune-associated cells (90). Exosomes may serve as potential therapeutic targets in ALS and prognostic markers for therapy in precision medicine through patient stratification.

\section{CONCLUSION}

The role of dysfunctional astrocytes in the pathogenesis of ALS indicates that astrocytes may be targeted with strategies for their revival. These strategies may include direct intervention on astrocytes with modulatory medicines, exosomes and miRNA-based therapies, or their replacement (Figure 4). Considering the first approach, activation of the nuclear factor erythroid 2-related factor (Nrf2) was shown to increase glutathione secretion; although some beneficial effects were observed on glial reactivity, it did not affect survival in mSOD1 mouse models (4). Reduction of reactive oxygen species production has been attempted, but again with no effective benefits (91). Another approach was the overexpression of MHC-I in MNs to enhance their resistance to the toxic factors released by the reactive astrocytes; this approach enhanced the survival of mSOD1 mice (33). As the aberrant astrocytes are associated with inflammatory and immune 


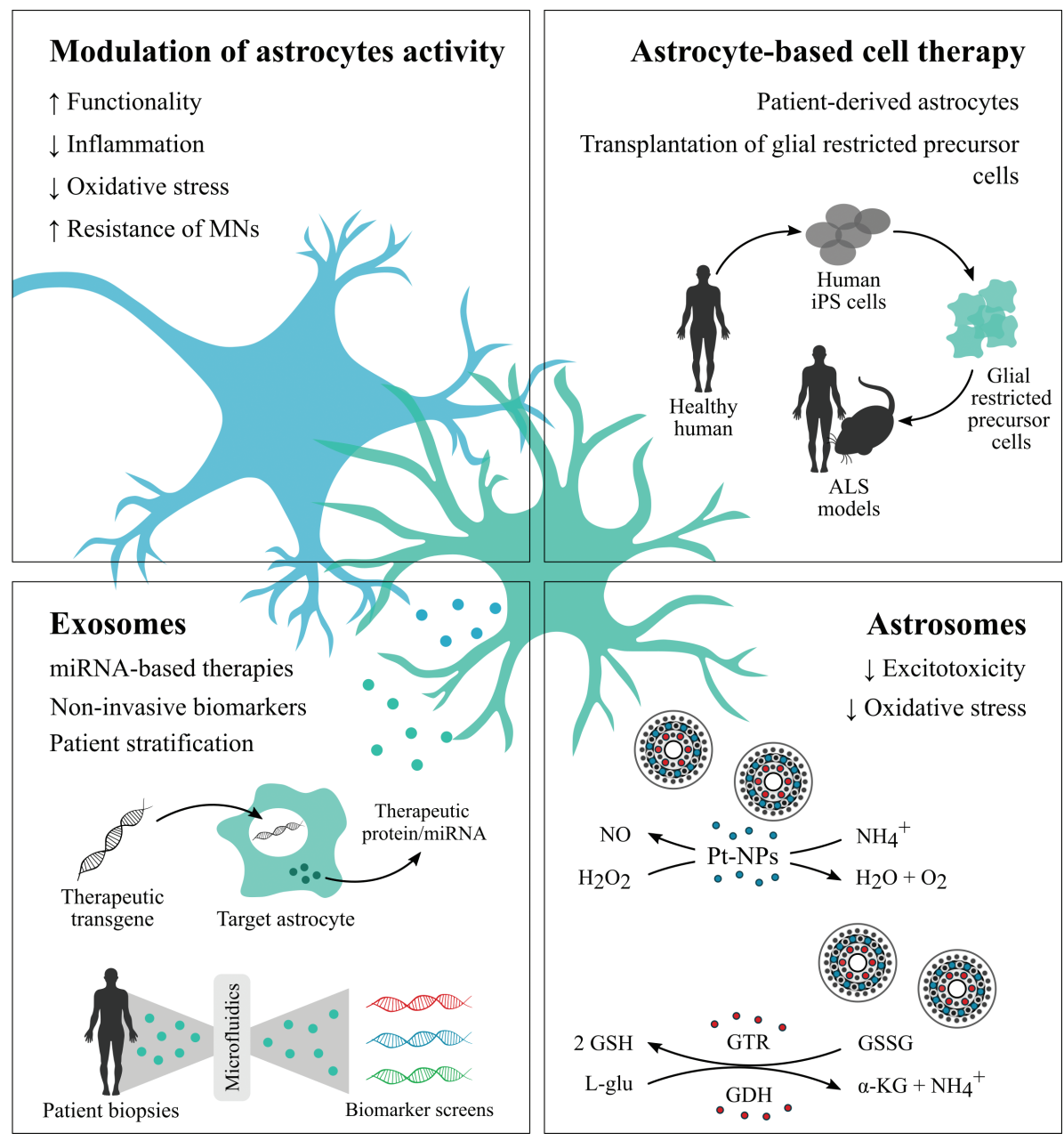

Figure 4. Targeting astrocytes for therapy. For functional recovery, astrocyte intervention strategies for ALS may include the modulation of astrocytic activity by using medicines or exosomes, astrocyte-based cell transplantation, and astrosomes (98). The switch of the phenotypic aberrancies and dysfunctionalities of the cell toward the steady-state astrocyte phenotype may include the inhibition of inflammatory mechanisms and oxidative stress $(4,36)$, increased resilience to paracrine toxic or inflammatory mediators released by MNs and activated microglia, or the boost of the cell, if senescent. Another possibility is the delivery of miRNA-based therapies, using miRNA mimics and/or inhibitors (36). For astrocyte-based cell therapy, patient-derived astrocytes, and glial progenitor cells/glial restricted precursor cells (4) may be used. The delivery of astrosomes, as artificial astrocytes, is an alternative strategy based on their ability to scavenge hydrogen peroxide, ROS, and ammonia, thus decreasing the excitotoxicity and the oxidative stress associated with ALS (96-98). ALS, amyotrophic lateral sclerosis; GDH, glutamate dehydrogenase; GSH, reduced glutathione; GTR, glutathione reductase; GSSG, oxidized glutathione; $\mathrm{H}_{2} \mathrm{O}_{2}$, hydrogen

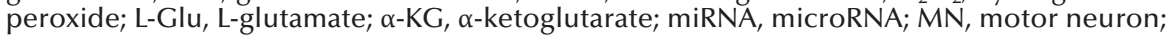
$\mathrm{NH}_{4}{ }^{+}$, ammonia; $\mathrm{NO}$, nitric oxide; Pt-NP, platinum nanoparticle; $\mathrm{ROS}$, reactive oxygen species. 
mechanisms $(15,17)$, modulation of such mechanisms with specific miRNAbased strategies may prevent cell-to-cell paracrine dysregulation and MN degeneration $(81,86)$.

The use of patient-derived astrocytes by reprogramming techniques brought new possibilities of therapeutic intervention, mainly because drug testing can be done in cells from sALS patients $(92,93)$. Transplantation of glial restricted precursor cells (94), combined with strategies capable of defending these cells from local toxicity (4), may represent innovative therapeutic approaches for ALS. Transplantation of neural progenitor cells expressing GDNF into the motor cortex of mSOD1 rats showed promise in extending their survival (95). Moreover, Armada-Moreira and colleagues developed an artificial astrocyte ("astrosome") capable of scavenging hydrogen peroxide and ammonia, by using platinum nanoparticles as artificial enzymes, as well as enzymes capable of glutamate degradation (96-98). Therefore, these microreactors have the potential to provide a therapeutic approach for several neurological diseases, such as ALS, in which oxidative stress and excitotoxicity are observed. We now have the possibility to work with human astrocytes differentiated from sALS and fALS patients and soon it will be possible to identify new targets and stratify patient astrocyte phenotypes, by using 3D microfluidic system models, and test promising therapeutics. Ultimately, this will provide a better understanding of the contribution of astrocytes in ALS, and how we might apply novel therapeutic strategies aimed at producing the revival of astrocytes, or even their replacement, and help in halting, or at least delaying ALS progression.

Acknowledgment: This work was supported by project funding from Fundação para a Ciência e para a Tecnologia (FCT) to SHV (PTDC/BTM-SAL/32147/2017), AMS (PTDC/MED-FAR/30933/2017) and to DB (PTDC/MED-NEU/31395/2017; LISBOA-01-0145-FEDER-031395, and UID/DTP/04138/2018), as well as from Santa Casa da Misericórdia (ALS Research Grant ELA-2015-002 to DB). This project has received funding from H2020-WIDESPREAD-05-2017-Twinning (EpiEpinet) under grant agreement No. 952455. SP (SFRH/BD/147277/2019) is a FCT PhD grant recipient.

Conflict of interest: The authors declare no potential conflict of interest with respect to research, authorship and/or publication of this manuscript.

Copyright and permission statement: The authors confirm that the materials included in this chapter do not violate copyright laws. Where relevant, appropriate permissions have been obtained from the original copyright holder(s), and all original sources have been appropriately acknowledged or referenced.

\section{REFERENCES}

1. Armada-Moreira A, Gomes JI, Pina CC, Savchak OK, Gonçalves-Ribeiro J, Rei N, et al. Going the Extra (Synaptic) Mile: Excitotoxicity as the Road Toward Neurodegenerative Diseases. Front Cell Neurosci. 2020 Apr 24;14:90. https://doi.org/10.3389/fncel.2020.00090 
2. Kiernan MC, Vucic S, Cheah BC, Turner MR, Eisen A, Hardiman O, et al. Amyotrophic lateral sclerosis. Lancet. 2011;377(9769):942-55. https://doi.org/10.1016/S0140-6736(10)61156-7

3. Byrne S, Elamin M, Bede P, Shatunov A, Walsh C, Corr B, et al. Cognitive and clinical characteristics of patients with amyotrophic lateral sclerosis carrying a C9orf72 repeat expansion: A population-based cohort study. Lancet Neurol. 2012;11(3):232-40. https://doi.org/10.1016/ S1474-4422(12)70014-5

4. Pehar M, Harlan BA, Killoy KM, Vargas MR. Role and Therapeutic Potential of Astrocytes in Amyotrophic Lateral Sclerosis. Curr Pharm Des. 2018;23(33). https://doi.org/10.2174/13816128236 66170622095802

5. Nagai M, Re DB, Nagata T, Chalazonitis A, Jessell TM, Wichterle H, et al. Astrocytes expressing ALS-linked mutated SODl release factors selectively toxic to motor neurons. Nat Neurosci. 2007;10(5):615-22. https://doi.org/10.1038/nn1876

6. Haidet-Phillips AM, Hester ME, Miranda CJ, Meyer K, Braun L, Frakes A, et al. Astrocytes from familial and sporadic ALS patients are toxic to motor neurons. Nat Biotechnol. 2011;29(9):824-8. https:// doi.org/10.1038/nbt.1957

7. Reischauer C, Gutzeit A, Neuwirth C, Fuchs A, Sartoretti-Schefer S, Weber M, et al. In-vivo evaluation of neuronal and glial changes in amyotrophic lateral sclerosis with diffusion tensor spectroscopy. NeuroImage Clin. 2018;20:993-1000. https://doi.org/10.1016/j.nicl.2018.10.001

8. Stamenković S, Dučić T, Stamenković V, Kranz A, Andjus PR. Imaging of glial cell morphology, SOD1 distribution and elemental composition in the brainstem and hippocampus of the ALS hSOD1G93A rat. Neuroscience. 2017;357:37-55. https://doi.org/10.1016/j.neuroscience.2017.05.041

9. Papadeas ST, Kraig SE, O'Banion C, Lepore AC, Maragakis NJ. Astrocytes carrying the superoxide dismutase 1 (SODl G93A) mutation induce wild-type motor neuron degeneration in vivo. Proc Natl Acad Sci U S A. 2011;108(43):17803-8. https://doi.org/10.1073/pnas.1103141108

10. Lepore AC, Rauck B, Dejea C, Pardo AC, Rao MS, Rothstein JD, et al. Focal transplantation-based astrocyte replacement is neuroprotective in a model of motor neuron disease. Nat Neurosci. 2008;11(11):1294-301. https://doi.org/10.1038/nn.2210

11. Qian K, Huang H, Peterson A, Hu B, Maragakis NJ, Ming G li, et al. Sporadic ALS Astrocytes Induce Neuronal Degeneration In Vivo. Stem Cell Reports. 2017;8(4):843-55. https://doi.org/10.1016/j. stemcr.2017.03.003

12. Gomes C, Sequeira C, Barbosa M, Cunha C, Vaz AR, Brites D. Astrocyte regional diversity in ALS includes distinct aberrant phenotypes with common and causal pathological processes. Exp Cell Res. 2020;395(2):112209. https://doi.org/10.1016/j.yexcr.2020.112209

13. Matias I, Morgado J, Gomes FCA. Astrocyte Heterogeneity: Impact to Brain Aging and Disease. Front Aging Neurosci. 2019;11:59. https://doi.org/10.3389/fnagi.2019.00059

14. Hu X, Yuan Y, Wang D, Su Z. Heterogeneous astrocytes: Active players in CNS. Brain Res Bull. 2016;125:1-18. https://doi.org/10.1016/j.brainresbull.2016.03.017

15. Gomes C, Cunha C, Nascimento F, Ribeiro JA, Vaz AR, Brites D. Cortical Neurotoxic Astrocytes with Early ALS Pathology and miR-146a Deficit Replicate Gliosis Markers of Symptomatic SODIG93A Mouse Model. Mol Neurobiol. 2019;56(3):2137-58. https://doi.org/10.1007/s12035-018-1220-8

16. Díaz-Amarilla P, Olivera-Bravo S, Trias E, Cragnolini A, Martinez-Palma L, Cassina P, et al. Phenotypically aberrant astrocytes that promote motoneuron damage in a model of inherited amyotrophic lateral sclerosis. Proc Natl Acad Sci U S A. 2011;108(44):18126-31. https://doi.org/10.1073/ pnas. 1110689108

17. Cunha C, Santos C, Gomes C, Fernandes A, Correia AM, Sebastião AM, et al. Downregulated Glia Interplay and Increased miRNA-155 as Promising Markers to Track ALS at an Early Stage. Mol Neurobiol. 2018;55(5):4207-24. https://doi.org/10.1007/s12035-017-0631-2

18. Eng LF, Vanderhaeghen JJ, Bignami A, Gerstl B. An acidic protein isolated from fibrous astrocytes. Brain Res. 1971;28(2):351-4. https://doi.org/10.1016/0006-8993(71)90668-8

19. Eng LF, Ghirnikar RS, Lee YL. Glial Fibrillary Acidic Protein: GFAP-Thirty-One Years (1969-2000). Neurochem Res. 2000;25(9-10):1439-51. https://doi.org/10.1023/A:1007677003387

20. Hol EM, Pekny M. Glial fibrillary acidic protein (GFAP) and the astrocyte intermediate filament system in diseases of the central nervous system [Internet]. Curr Opin Cell Biol. 2015;32:121-30. https://doi.org/10.1016/j.ceb.2015.02.004 
21. Fujita K, Kato T, Yamauchi M, Ando M, Honda M, Nagata Y. Increases in fragmented glial fibrillary acidic protein levels in the spinal cords of patients with amyotrophic lateral sclerosis. Neurochem Res. 1998;23(2):169-74. https://doi.org/10.1023/A:1022476724381

22. Benninger F, Glat MJ, Offen D, Steiner I. Glial fibrillary acidic protein as a marker of astrocytic activation in the cerebrospinal fluid of patients with amyotrophic lateral sclerosis. J Clin Neurosci. 2016;26:75-8. https://doi.org/10.1016/j.jocn.2015.10.008

23. Tripathi P, Rodriguez-Muela N, Klim JR, de Boer AS, Agrawal S, Sandoe J, et al. Reactive Astrocytes Promote ALS-like Degeneration and Intracellular Protein Aggregation in Human Motor Neurons by Disrupting Autophagy through TGF- $\beta 1$. Stem Cell Reports. 2017;9(2):667-80. https://doi. org/10.1016/j.stemcr.2017.06.008

24. Almer G, Vukosavic S, Romero N, Przedborski S. Inducible nitric oxide synthase up-regulation in a transgenic mouse model of familial amyotrophic lateral sclerosis. J Neurochem. 1999;72(6):2415-25. https://doi.org/10.1046/j.1471-4159.1999.0722415.x

25. Alexianu ME, Kozovska M, Appel SH. Immune reactivity in a mouse model of familial ALS correlates with disease progression. Neurology. 2001;57(7):1282-9. https://doi.org/10.1212/WNL.57.7.1282

26. Sidoryk-Wegrzynowicz M, Gerber YN, Ries M, Sastre M, Tolkovsky AM, Spillantini MG. Astrocytes in mouse models of tauopathies acquire early deficits and lose neurosupportive functions. Acta Neuropathol Commun. 2017;5(1):89. https://doi.org/10.1186/s40478-017-0478-9

27. Kunze A, Lengacher S, Dirren E, Aebischer P, Magistretti PJ, Renaud P. Astrocyte-neuron co-culture on microchips based on the model of SOD mutation to mimic ALS. Integr Biol (United Kingdom). 2013;5(7):964-75. https://doi.org/10.1039/c3ib40022k

28. Yoshii Y, Otomo A, Pan L, Ohtsuka M, Hadano S. Loss of glial fibrillary acidic protein marginally accelerates disease progression in a SODl H46R transgenic mouse model of ALS. Neurosci Res. 2011;70(3):321-9. https://doi.org/10.1016/j.neures.2011.03.006

29. Casula M, Iyer AM, Spliet WGM, Anink JJ, Steentjes K, Sta M, et al. Toll-like receptor signaling in amyotrophic lateral sclerosis spinal cord tissue. Neuroscience. 2011;179:233-43. https://doi. org/10.1016/j.neuroscience.2011.02.001

30. Süssmuth SD, Sperfeld AD, Hinz A, Brettschneider J, Endruhn S, Ludolph AC, et al. CSF glial markers correlate with survival in amyotrophic lateral sclerosis. Neurology. 2010;74(12):982-7. https://doi. org/10.1212/WNL.0b013e3181d5dc3b

31. Ouali Alami N, Schurr C, Olde Heuvel F, Tang L, Li Q, Tasdogan A, et al. NF-kB activation in astrocytes drives a stage-specific beneficial neuroimmunological response in ALS. EMBO J. 2018;37(16). https://doi.org/10.15252/embj.201798697

32. Spitale FM, Vicario N, Di Rosa M, Tibullo D, Vecchio M, Gulino R, et al. Increased expression of connexin 43 in a mouse model of spinal motoneuronal loss. Aging (Albany NY). 2020;12(13):12598-608. https://doi.org/10.18632/aging.103561

33. Song S, Miranda CJ, Braun L, Meyer K, Frakes AE, Ferraiuolo L, et al. Major histocompatibility complex class I molecules protect motor neurons from astrocyte-induced toxicity in amyotrophic lateral sclerosis. Nat Med. 2016;22(4):397-403. https://doi.org/10.1038/nm.4052

34. Mishra PS, Dhull DK, Nalini A, Vijayalakshmi K, Sathyaprabha TN, Alladi PA, et al. Astroglia acquires a toxic neuroinflammatory role in response to the cerebrospinal fluid from amyotrophic lateral sclerosis patients. J Neuroinflammation. 2016;13(1). https://doi.org/10.1186/s12974-016-0698-0

35. Liddelow SA, Guttenplan KA, Clarke LE, Bennett FC, Bohlen CJ, Schirmer L, et al. Neurotoxic reactive astrocytes are induced by activated microglia. Nature. 2017;541(7638):481-7. https://doi. org/10.1038/nature21029

36. Guttenplan KA, Weigel MK, Adler DI, Couthouis J, Liddelow SA, Gitler AD, et al. Knockout of reactive astrocyte activating factors slows disease progression in an ALS mouse model. Nat Commun. 2020;11(1). https://doi.org/10.1038/s41467-020-17514-9

37. Buskila Y, Kékesi O, Bellot-Saez A, Seah W, Berg T, Trpceski M, et al. Dynamic interplay between H-current and M-current controls motoneuron hyperexcitability in amyotrophic lateral sclerosis. Cell Death Dis. 2019;10(4). https://doi.org/10.1038/s41419-019-1538-9

38. Birger A, Ben-Dor I, Ottolenghi M, Turetsky T, Gil Y, Sweetat S, et al. Human iPSC-derived astrocytes from ALS patients with mutated C9ORF72 show increased oxidative stress and neurotoxicity. EBioMedicine. 2019;50:274-89. https://doi.org/10.1016/j.ebiom.2019.11.026 
39. Martínez-Silva M de L, Imhoff-Manuel RD, Sharma A, Heckman CJ, Shneider NA, Roselli F, et al. Hypoexcitability precedes denervation in the large fast-contracting motor units in two unrelated mouse models of ALS. Elife. 2018;7. https://doi.org/10.7554/eLife.30955

40. Gonçalves-Ribeiro J, Pina CC, Sebastião AM, Vaz SH. Glutamate Transporters in Hippocampal LTD/ LTP: Not Just Prevention of Excitotoxicity. Front Cell Neurosci. 2019;13:357. https://doi.org/10.3389/ fncel.2019.00357

41. Wallis N, Lau CL, Farg MA, Atkin JD, Beart PM, O'Shea RD. SODl Mutations Causing Familial Amyotrophic Lateral Sclerosis Induce Toxicity in Astrocytes: Evidence for Bystander Effects in a Continuum of Astrogliosis. Neurochem Res. 2018;43(1):157-70. https://doi.org/10.1007/ s11064-017-2385-7

42. Barton SK, Lau CL, Chiam MDF, Tomas D, Muyderman H, Beart PM, et al. Mutant TDP-43 Expression Triggers TDP-43 Pathology and Cell Autonomous Effects on Primary Astrocytes: Implications for Noncell Autonomous Pathology in ALS. Neurochem Res. 2020;45(6):1451-9. https://doi.org/10.1007/ sl1064-020-03048-5

43. Sasaki S, Komori T, Iwata M. Excitatory amino acid transporter 1 and 2 immunoreactivity in the spinal cord in amyotrophic lateral sclerosis. Acta Neuropathol. 2000;100(2):138-44. https://doi. org/10.1007/s004019900159

44. Bendotti C, Tortarolo M, Suchak SK, Calvaresi N, Carvelli L, Bastone A, et al. Transgenic SOD1 G93A mice develop reduced GLT-1 in spinal cord without alterations in cerebrospinal fluid glutamate levels. J Neurochem. 2001;79(4):737-46. https://doi.org/10.1046/j.1471-4159.2001.00572.x

45. Tong J, Huang C, Bi F, Wu Q, Huang B, Liu X, et al. Expression of ALS-linked TDP-43 mutant in astrocytes causes non-cell-autonomous motor neuron death in rats. EMBO J. 2013;32(13):1917-26. https://doi.org/10.1038/emboj.2013.122

46. Boycott HE, Wilkinson JA, Boyle JP, Pearson HA, Peers C. Differential involvement of TNF $\alpha$ in hypoxic suppression of astrocyte glutamate transporters. Glia. 2008;56(9):998-1004. https://doi. org/10.1002/glia.20673

47. Jiang LL, Zhu B, Zhao Y, Li X, Liu T, Pina-Crespo J, et al. Membralin deficiency dysregulates astrocytic glutamate homeostasis leading to ALS-like impairment. J Clin Invest. 2019;129(8):3103-20. https:// doi.org/10.1172/JCI127695

48. Yin X, Wang S, Qi Y, Wang X, Jiang H, Wang T, et al. Astrocyte elevated gene-1 is a novel regulator of astrogliosis and excitatory amino acid transporter-2 via interplaying with nuclear factor- $\mathrm{k}$ s signaling in astrocytes from amyotrophic lateral sclerosis mouse model with hSODIG93A mutation. Mol Cell Neurosci. 2018;90:1-11. https://doi.org/10.1016/j.mcn.2018.05.004

49. Rosenblum LT, Shamamandri-Markandaiah S, Ghosh B, Foran E, Lepore AC, Pasinelli P, et al. Mutation of the caspase-3 cleavage site in the astroglial glutamate transporter EAAT2 delays disease progression and extends lifespan in the SOD1-G93A mouse model of ALS. Exp Neurol. 2017;292:145-53. https:// doi.org/10.1016/j.expneurol.2017.03.014

50. Li K, Hala TJ, Seetharam S, Poulsen DJ, Wright MC, Lepore AC. GLTl overexpression in SOD1G93A mouse cervical spinal cord does not preserve diaphragm function or extend disease. Neurobiol Dis. 2015;78:12-23. https://doi.org/10.1016/j.nbd.2015.03.010

51. Kong Q, Chang LC, Takahashi K, Liu Q, Schulte DA, Lai L, et al. Small-molecule activator of glutamate transporter EAAT2 translation provides neuroprotection. J Clin Invest. 2014;124(3):1255-67. https://doi.org/10.1172/JCI66163

52. Lapucci A, Cavone L, Buonvicino D, Felici R, Gerace E, Zwergel C, et al. Effect of Class II HDAC inhibition on glutamate transporter expression and survival in SODl-ALS mice. Neurosci Lett. 2017;656:120-5. https://doi.org/10.1016/j.neulet.2017.07.033

53. Panatier A, Vallée J, Haber M, Murai KK, Lacaille JC, Robitaille R. Astrocytes are endogenous regulators of basal transmission at central synapses. Cell. 2011;146(5):785-98. https://doi.org/10.1016/j. cell.2011.07.022

54. Milanese M, Giribaldi F, Melone M, Bonifacino T, Musante I, Carminati E, et al. Knocking down metabotropic glutamate receptor 1 improves survival and disease progression in the SOD1G93A mouse model of amyotrophic lateral sclerosis. Neurobiol Dis. 2014;64:48-59. https://doi.org/10.1016/j. nbd.2013.11.006 
55. Bonifacino T, Cattaneo L, Gallia E, Puliti A, Melone M, Provenzano F, et al. In-vivo effects of knockingdown metabotropic glutamate receptor 5 in the SODIG93A mouse model of amyotrophic lateral sclerosis. Neuropharmacology. 2017;123:433-45. https://doi.org/10.1016/j.neuropharm.2017.06.020

56. Vermeiren C, De Hemptinne I, Vanhoutte N, Tilleux S, Maloteaux JM, Hermans E. Loss of metabotropic glutamate receptor-mediated regulation of glutamate transport in chemically activated astrocytes in a rat model of amyotrophic lateral sclerosis. J Neurochem. 2006;96(3):719-31. https://doi. org/10.1111/j.1471-4159.2005.03577.x

57. Vergouts M, Doyen PJ, Peeters M, Opsomer R, Hermans E. Constitutive downregulation protein kinase C epsilon in hSOD1G93A astrocytes influences mGluR5 signaling and the regulation of glutamate uptake. Glia. 2018;66(4):749-61. https://doi.org/10.1002/glia.23279

58. Raiteri L, Paolucci E, Prisco S, Raiteri M, Bonanno G. Activation of a glycine transporter on spinal cord neurons causes enhanced glutamate release in a mouse model of amyotrophic lateral sclerosis. $\mathrm{Br} \mathrm{J}$ Pharmacol. 2003;138(6):1021-5. https://doi.org/10.1038/sj.bjp.0705142

59. Milanese M, Bonifacino T, Fedele E, Rebosio C, Cattaneo L, Benfenati F, et al. Exocytosis regulates trafficking of GABA and glycine heterotransporters in spinal cord glutamatergic synapses: A mechanism for the excessive heterotransporter-induced release of glutamate in experimental amyotrophic lateral sclerosis. Neurobiol Dis. 2015;74:314-24. https://doi.org/10.1016/j.nbd.2014.12.004

60. Raiteri L, Stigliani S, Usai C, Diaspro A, Paluzzi S, Milanese M, et al. Functional expression of releaseregulating glycine transporters GLYT1 on GABAergic neurons and GLYT2 on astrocytes in mouse spinal cord. Neurochem Int. 2008;52(1):103-12. https://doi.org/10.1016/j.neuint.2007.04.027

61. Milanese M, Zappettini S, Jacchetti E, Bonifacino T, Cervetto C, Usai C, et al. In vitro activation of GAT1 transporters expressed in spinal cord gliosomes stimulates glutamate release that is abnormally elevated in the SOD1/G93A(+) mouse model of amyotrophic lateral sclerosis. J Neurochem. 2010;113(2):489-501. https://doi.org/10.1111/j.1471-4159.2010.06628.x

62. Kazama M, Kato Y, Kakita A, Noguchi N, Urano Y, Masui K, et al. Astrocytes release glutamate via cystine/glutamate antiporter upregulated in response to increased oxidative stress related to sporadic amyotrophic lateral sclerosis. Neuropathology. 2020;40(6):587-98. https://doi.org/10.1111/ neup. 12716

63. Madji Hounoum B, Mavel S, Coque E, Patin F, Vourc'h P, Marouillat S, et al. Wildtype motoneurons, ALS-Linked SOD1 mutation and glutamate profoundly modify astrocyte metabolism and lactate shuttling. Glia. 2017;65(4):592-605. https://doi.org/10.1002/glia.23114

64. Di Gioia D, Bozzi Cionci N, Baffoni L, Amoruso A, Pane M, Mogna L, et al. A prospective longitudinal study on the microbiota composition in amyotrophic lateral sclerosis. BMC Med. 2020;18(1). https:// doi.org/10.1186/s12916-020-01607-9

65. Kofuji P, Araque A. G-Protein-Coupled Receptors in Astrocyte-Neuron Communication. Neuroscience. 2021;456:71-84. https://doi.org/10.1016/j.neuroscience.2020.03.025

66. Verkhratsky A, Reyes RC, Parpura V. TRP channels coordinate ion signalling in astroglia. Rev Physiol Biochem Pharmacol. 2014;166. https://doi.org/10.1007/112_2013_15

67. Agarwal A, Wu PH, Hughes EG, Fukaya M, Tischfield MA, Langseth AJ, et al. Transient Opening of the Mitochondrial Permeability Transition Pore Induces Microdomain Calcium Transients in Astrocyte Processes. Neuron. 2017;93(3):587-605.e7. https://doi.org/10.1016/j.neuron.2016.12.034

68. Verkhratsky A. Astroglial calcium signaling in aging and alzheimer's disease. Cold Spring Harb Perspect Biol. 2019;11(7). https://doi.org/10.1101/cshperspect.a035188

69. Kawamata H, Manfredi G. Mitochondrial dysfunction and intracellular calcium dysregulation in ALS. Mech Ageing Dev. 2010;131(7-8):517-26. https://doi.org/10.1016/j.mad.2010.05.003

70. Martorana F, Brambilla L, Valori CF, Bergamaschi C, Roncoroni C, Aronica E, et al. The BH4 domain of Bcl-X L rescues astrocyte degeneration in amyotrophic lateral sclerosis by modulating intracellular calcium signals. Hum Mol Genet. 2012;21(4):826-40. https://doi.org/10.1093/hmg/ddr513

71. Rossi D, Brambilla L, Valori CF, Roncoroni C, Crugnola A, Yokota T, et al. Focal degeneration of astrocytes in amyotrophic lateral sclerosis. Cell Death Differ. 2008;15(11):1691-700. https://doi. org/10.1038/cdd.2008.99

72. Kawamata H, Ng SK, Diaz N, Burstein S, Morel L, Osgood A, et al. Abnormal intracellular calcium signaling and SNARE dependent exocytosis contributes to SODIG93A astrocyte- mediated 
toxicity in amyotrophic lateral sclerosis. J Neurosci. 2014;34(6):2331-48. https://doi.org/10.1523/ JNEUROSCI.2689-13.2014

73. Almad AA, Doreswamy A, Gross SK, Richard JP, Huo Y, Haughey N, et al. Connexin 43 in astrocytes contributes to motor neuron toxicity in amyotrophic lateral sclerosis. Glia. 2016;64(7):1154-69. https://doi.org/10.1002/glia.22989

74. Gandelman M, Peluffo H, Beckman JS, Cassina P, Barbeito L. Extracellular ATP and the P2X7receptor in astrocyte-mediated motor neuron death: Implications for amyotrophic lateral sclerosis. J Neuroinflammation. 2010;7. https://doi.org/10.1186/1742-2094-7-33

75. Apolloni S, Amadio S, Parisi C, Matteucci A, Potenza RL, Armida M, et al. Spinal cord pathology is ameliorated by P2X7 antagonism in a SOD1-mutant mouse model of amyotrophic lateral sclerosis. DMM Dis Model Mech. 2014;7(9):1101-9. https://doi.org/10.1242/dmm.017038

76. Sebastião AM, Assaife-Lopes N, Diógenes MJ, Vaz SH, Ribeiro JA. Modulation of brain-derived neurotrophic factor (BDNF) actions in the nervous system by adenosine A2A receptors and the role of lipid rafts. Biochimica et Biophysica Acta (BBA) - Biomembranes. 2011;1808(5):1340-1349. https://doi. org/10.1016/j.bbamem.2010.06.028

77. Pradhan J, Noakes PG, Bellingham MC. The Role of Altered BDNF/TrkB Signaling in Amyotrophic Lateral Sclerosis. Front Cell Neurosci. 2019;13:368. https://doi.org/10.3389/fncel.2019.00368

78. Brambilla L, Martorana F, Guidotti G, Rossi D. Dysregulation of astrocytic HMGB1 signaling in amyotrophic lateral sclerosis. Front Neurosci. 2018;12. https://doi.org/10.3389/fnins.2018.00622

79. Fritz E, Izaurieta P, Weiss A, Mir FR, Rojas P, Gonzalez D, et al. Mutant SODl-expressing astrocytes release toxic factors that trigger motoneuron death by inducing hyperexcitability. J Neurophysiol. 2013;109(11):2803-14. https://doi.org/10.1152/jn.00500.2012

80. Basso M, Pozzi S, Tortarolo M, Fiordaliso F, Bisighini C, Pasetto L, et al. Mutant Copper-Zinc Superoxide Dismutase (SOD1) Induces Protein Secretion Pathway Alterations and Exosome Release in Astrocytes: implications for disease spreading and motor neuron pathology in Amyotrophic Lateral Sclerosis. J Biol Chem. 2013;288(22):15699-711. https://doi.org/10.1074/jbc.M112.425066

81. Barbosa M, Gomes C, Sequeira C, Gonçalves-Ribeiro JF, Pina CC, Carvalho LA, et al. Recovery of depleted miR-146a in ALS cortical astrocytes reverts cell aberrancies and prevents paracrine pathogenicity on microglia and motor neurons. Front Cell Dev Biol. 2021;9:930. https://doi.org/10.3389/ fcell.2021.634355

82. Brites D. Regulatory function of microRNAs in microglia. Glia. 2020;68(8):1631-42. https://doi. org/10.1002/glia.23846

83. Hoye ML, Regan MR, Jensen LA, Lake AM, Reddy LV, Vidensky S, et al. Motor neuronderived microRNAs cause astrocyte dysfunction in amyotrophic lateral sclerosis. Brain. 2018;141(9):2561-75. https://doi.org/10.1093/brain/awyl82

84. Pinto S, Cunha C, Barbosa M, Vaz AR, Brites D. Exosomes from NSC-34 cells transfected with hSOD 1G93A are enriched in mir-124 and drive alterations in microglia phenotype. Front Neurosci. 2017;11. https://doi.org/10.3389/fnins.2017.00273

85. Fernandes A, Ribeiro AR, Monteiro M, Garcia G, Vaz AR, Brites D. Secretome from SH-SY5Y APP Swe cells trigger time-dependent CHME3 microglia activation phenotypes, ultimately leading to miR-21 exosome shuttling. Biochimie. 2018. https://doi.org/10.1016/j.biochi.2018.05.015

86. Butovsky O, Jedrychowski MP, Cialic R, Krasemann S, Murugaiyan G, Fanek Z, et al. Targeting miR-155 restores abnormal microglia and attenuates disease in SODl mice. Ann Neurol. 2015;77(1):75-99. https://doi.org/10.1002/ana.24304

87. Freischmidt A, Müller K, Zondler L, Weydt P, Volk AE, Božič AL, et al. Serum microRNAs in patients with genetic amyotrophic lateral sclerosis and pre-manifest mutation carriers. Brain. 2014;137(11):2938-50. https://doi.org/10.1093/brain/awu249

88. Joilin G, Leigh PN, Newbury SF, Hafezparast M. An Overview of MicroRNAs as Biomarkers of ALS. Front. Neurol. 10:186. https://doi.org/10.3389/fneur.2019.00186

89. Varcianna A, Myszczynska MA, Castelli LM, O'Neill B, Kim Y, Talbot J, et al. Micro-RNAs secreted through astrocyte-derived extracellular vesicles cause neuronal network degeneration in C9orf72 ALS. EBioMedicine. 2019;40:626-35. https://doi.org/10.1016/j.ebiom.2018.11.067 
90. Que RS, Lin C, Ding G ping, Wu Z rong, Cao L ping. Increasing the immune activity of exosomes: the effect of miRNA-depleted exosome proteins on activating dendritic cell/cytokine-induced killer cells against pancreatic cancer. J Zhejiang Univ Sci B. 2016;17(5):352-60. https://doi.org/10.1631/jzus. B1500305

91. Carrera-Juliá S, Moreno ML, Barrios C, de la Rubia Ortí JE, Drehmer E. Antioxidant Alternatives in the Treatment of Amyotrophic Lateral Sclerosis: A Comprehensive Review. Front Physiol. 2020;11:63. https://doi.org/10.3389/fphys.2020.00063

92. Vasques JF, Mendez-Otero R, Gubert F. Modeling ALS using iPSCs: Is it possible to reproduce the phenotypic variations observed in patients in vitro? [Internet]. Regen Med. 2020;15(7):1919-1933. https://doi.org/10.2217/rme-2020-0067

93. Meyer K, Ferraiuolo L, Miranda CJ, Likhite S, McElroy S, Renusch S, et al. Direct conversion of patient fibroblasts demonstrates non-cell autonomous toxicity of astrocytes to motor neurons in familial and sporadic ALS. Proc Natl Acad Sci U S A. 2014;111(2):829-32. https://doi.org/10.1073/ pnas. 1314085111

94. Martins-Macedo J, Lepore AC, Domingues HS, Salgado AJ, Gomes ED, Pinto L. Glial restricted precursor cells in central nervous system disorders: Current applications and future perspectives. Glia. 2021;69(3):513-31. https://doi.org/10.1002/glia.23922

95. Thomsen GM, Avalos P, Ma AA, Alkaslasi M, Cho N, Wyss L, et al. Transplantation of Neural Progenitor Cells Expressing Glial Cell Line-Derived Neurotrophic Factor into the Motor Cortex as a Strategy to Treat Amyotrophic Lateral Sclerosis. Stem Cells. 2018;36(7):1122-31. https://doi.org/10.1002/ stem. 2825

96. Armada-Moreira A, Taipaleenmäki E, Baekgaard-Laursen M, Schattling PS, Sebastião AM, Vaz SH, et al. Platinum Nanoparticle-Based Microreactors as Support for Neuroblastoma Cells. ACS Appl Mater Interfaces. 2018;10(9):7581-92. https://doi.org/10.1021/acsami.7b10724

97. Armada-Moreira A, Thingholm B, Andreassen K, Sebastião AM, Vaz SH, Städler B. On the Assembly of Microreactors with Parallel Enzymatic Pathways. Adv Biosyst. 2018;2(5):1700244. https://doi. org/10.1002/adbi.201700244

98. Armada-Moreira A, Coelho JE, Lopes L V., Sebastião AM, Städler B, Vaz SH. Multicompartment Microreactors Prevent Excitotoxic Dysfunctions In Rat Primary Cortical Neurons. Adv Biosyst. 2020;4(10). https://doi.org/10.1002/adbi.202000139 
